was severe pain, requiring much morphia. The pulse continued rapid, and the patient was still in a critical condition.

June 4th. It was evident that an abscess was forming in the peritoneal cavity, around the hole made in the cyst wall at the last operation. There was great pain, some vomiting; almost all food was refused. Pulse 130 , temperature $1020^{\circ}$ The patient was very low.

June 15th. I etherized her again for the third time since the operation. The intra-peritoneal abscess was opened, and a large quantity of stinking pus evacuated. I then began a systematic search in all directions to find retained pus, and, to my dismay, I found a sponge at the bottom of one of the cavities. This sponge had been crowded in to stop the bleeding from the papillomatous growth, when the patient collapsed at the first operation, and had long since been forgotten. Everything was thoroughly disinfected, and all the tubes replaced. After a time some of the cavities closed, and the cyst was more easily drained. The large cystcavity gradually contracted. Finally, we made a desperate effort to break off the morphia, but failed, and I am sure that the patient would have died if we had continued to withhold it. She gradually gained strength until the end of June, when she was moved from the hospital. At home she continued to improve. All the tubes were removed, except the long one, which ran through the cyst.

July 28th. She was so much improved that she was up and about the room; was taking only onequarter of a grain of morphia a day. The vaginal part of the tube was soon removed, and only a short tube remained in the abdominal opening. She went into the country for the summer, where she improved so much that when she walked into my office in October I did not recognize her. She had gained much flesh and strength. Since then she has been able to go about and enjoy life.

I saw her on October 21, 1886, when she told me that she had removed the tube a year ago, and that since that time the sinus would remain healed for several months at a time, but would suddenly break open and discharge pus for a few days, and then heal again. I found that the old tumor had disappeared, but that the small one on the other side had grown to the size of a cocoanut; I advised its removal.

It should be understood that the deplorable condition in which I first found the patient was due to the tapping which had been done several months previous. In spite of the outcry against tapping, we continue to meet patients suffering from that maltreatment.

Although we know from experience in ovariotomy that patients may tolerate an extraordinary amount of damage in the way of tearing out an adherent cyst wall, we also know that patients not infrequently die on the table, or soon after these most severe operations. Drainage offers a chance for some of the bad cases. I have taken pains to follow out these cases, in order to get a clear idea of the course and results of drainage. With this side of the picture complete, we shall be better prepared to decide in a given case whether to risk a very serious operation, or to go through with the tediousness of drainage. Schroeder and others have objected to drainage, on account of the tendency to recurrence. Rheinstaedter ${ }^{2}$ reports seven cases where more or less of the cyst was left and drained; all seven recovered without recurrence. Certainly, there has been nò special tendency to recurrence in my cases, and one was papillomatous, operated on one and a half years ago. If any of them recur in the future, $I$ have, at least, the satisfaction of giving them a year or two of comfortable life. It may also be possible to do another operation, under conditions more favorable than the first.

These cases have raised the question of how ovarian cysts discharging into the various cavities are best treated. If the cyst is discharging into the rectum or vagina, an attemp should be made to drain in that direction, as in cases I and II. If the cyst is discharging into the intestine or bladder, it should be removed by laparotomy, and the opening into intestine or bladder closed by suture.

\section{THE MALE URETHRA. ${ }^{1}$}

SOME NEW AND PRACTICAL OBSERVATIONS ON ITS ANATOMY IN RELATION TO ENDOSCOPY, LITHOLOPAXY, AND CATHETERIZATION.

BY OTIS K. NEWELL, M.D.,

Assistant in Anatomy at the Harvard Medical School.

DURING the early part of the present year, it occurred to me, in observing a case of litholopaxy at the Massachusetts General Hospital, that there could be no reason why the same sized tubes which so readily enter the normal urethra could not be applied to advantage in an endoscopic examination of the bladder, urethra, and other parts. I trust that the results of my investigation in this connection will not fail to be of interest and value. Three years ago, at Professor Dittel's clinic in Vienna, I had occasion to make an endoscopic examination of the urethra, with the instrument there in vogue, and from what I was enabled to see through its small calibre, together with Professor Dittel's rather sceptical views in regard to its gereral utility, I gave but little further attention to the subject of endoscopy. Having had made a No. 30 tube, however, a more particular description of which will be given further on, I was much surprised and gratified to find with what readiness and satisfaction the surface of the bladder or urethra could be examined by means of light thrown in by the ordinary laryngoscopic mirror. My first examinations were made upon the cadaver, and there the mucous membrane could be plainly seen, and any small body, such as a piece of sponge, a tack or screw, when introduced into the bladder, readily found and recognized. That bodies of considerable size could be easily introduced through the 30-tube naturally led to thoughts of instrumentation within the bladder, and of this I will speak more fully later on. The first tube I had made was one corresponding in length to the ordinary catheter, cut off at the lower or visceral end obliquely, at an angle of about $45^{\circ}$, and closed with a thin plate of glass. This, I later learned, corresponded much with Grünfeld's straight, fenestrated endoscope, and was designed to prevent the entrance of urine into the tube, and admit of inspection by placing the glass against the bladder wall. The rather obscure picture through the glass, however, led me to soon abandon this for a similar open tube, into which a staff, or guide, was inserted for its better introduction. 
Since the clearness of view through the tube depended upon the amount of light thrown in, and this was determined by the length of the endoscope, I next endeavored to ascertain how short an instrument could be, and still admit of ready introduction into the bladder. The examination of a large number of cases for this purpose has led to what has been, to me, an astonishing result, considering the previous knowledge of this subject, at least, in its application. I find, namely, that an instrument, catheter, sound, or evacuating tube, having a length of five inches or more, can be readily introduced through the urethra into the bladder of any normal subject, the requisite manipulation being but little more difficult than that required in the introduction of instruments having the traditional measurement.

The pendulous portion of the urethra, the part anterior to the triangular ligament, can be readily folded together, so that its long axis occupies not more than from one and a half to two inches. I have found no case where an endoscope six inches in length could not be introduced into the bladder, so as to have two inches or more protruding from the visceral orifice. 'I'o ascertain this, I have made careful measurements of fifteen adult urethræ in subjects from thirty to seventy years of age, besides examining quite a large number of unrecorded cases. The length of the posterior urethra, made up of the membranous and prostatic portions, varies but little, the prostatic portion averaging about one and one fourth inches, and the measurement of the membranous region three-quarters of an inch or less. An enlarged prostate seldom increases the length of this portion to any great degree, the growth being mostly rateral, and affecting more its calibre and direction, the middle lobe, when much enlarged, standing as an obstruction before the vesical orifice.

We have then, in the male subject, an urethra, the posterior portion of which averages two inches in length, and presents beyond this, as its continuation, a canal which, from its anatomical structure, and that of its surrounding parts, is readily folded together, so as to have the same length, the variation in different individuals, when the urethra is thus apposed, being of no considerable degree.

The applied anatomy of the male urethra, then, is such that we may consider the length of this canal to be, for surgical purposes, but four inches, increased, in cases of enormous hypertrophy, to a possible six. Better than to further attempt the demonstration of this fact, I will leave it to the more convincing investigation of those of you to whom it may be of interest, and consider at once its application to the subjects indicated in the title of my paper.

\section{ENDOSCOPY.}

After becoming interested in this subject, I carefully read the admirable and voluminous work of Pro. fessor Grünfeld, who, by adopting the simple laryngoscopic mirror as a light source, and making numerous improvements in the endoscopic instruments, together with the most patient and systematic labor, has accomplished more than any of the recent workers on this subject. To all who may be interested in it, his book will prove of great value. It is sufficient to mention here that to the endoscope we owe most of our exact knowledge of urethral pathology, and an idea of what patient work with this instrument in the hands of Boz- zini, Désormeaux, Grünfeld, and others has accomplished, may be obtained by quoting from the index to the illustrated plates in Grünfeld's work : 43, Urethritis Simplex; 48, Urethritis Granulosa, with rigid walls; 55-58, Two Ulcers on the urethral mucous membrane of a man ; 59, Urethral Chancre; 61, Primary lesion of syphilis during cicatrization, the rigidity of the walls permitting the introduction of the endoscope into the healthy urethra beyond; 66, Epithelial thickening of the mucosa in stricture after partial dilatation; 79, Stricture, with a bridge apparently two openings into the urethra beyond; 81, Stricture of long standing after thorough dilatation (22, Charriere); 82, Urethral polyp on the posterior wall of the urethra; 97-101, Pictures taken from an urethral carcinoma ; 103, Posterior portion of a diverticulum on the lower urethral.wall; 102 , Tumor of the mucous membrane of the bladder in cystitis; 108 , Cicatrix following a vesico vaginal fistula.

Notwithstanding all this, however, the endoscope has hitherto been chiefly applied to the examination of urethral diseases, and since the cases where its use in this connection is of great practical value are the exception, I will only consider its application in the modified form which I have ventured to construct.

The endoscope which I have had made (Fig. 1) differs from Grünfeld's, first, in having a 30-calibre determined by that of the normal urethra, 30 to 33 , Grünfeld's tubes never being made larger than 24 , and averaging from 18 to 20 . Second, in the obliquity of its visceral opening, so that inspection in all directions is made possible by the protrusion of the bladder wall or mucous membrane into its orifice. Grünfeld's straight, fenestrated tube has the window set in at a slight angle, in order to avoid light reflexes, but that author recommends only the tubes cut off at a right angle to the axis for.general use, and never any with more than a slight variation from a right angle. Such tubes are undoubtedly best for urethral examination. Third, in being particularly designed for the inspection of the bladder, and permitting what has hitherto not been done, the introduction of instruments through an endoscope into the male bladder, so that, as with the forceps which I have had constructed for the purpose, a foreign body might be removed in this manner, instead of by operation, or with a lithotrite.

For the female bladder and urethra the instruments are similar, but much shorter, and may be of larger calibre. The external orifice of the female urethra, however, is not always larger than that of the male, and often requires forcible dilatation before admitting the introduction of instruments of large calibre.

My instrunient is principally designed for the detection of foreign bodies and growths in the bladder, and as an aid in the solution of obscure symptoms of urethral and bladder disease. The fenestrated tube may be used with advantage in preliminary examination, as the mucous membrane and its vascular supply are much better seen in the full bladder. The open tube is used in the empty bladder, absorbent cotton or sponge tampons may be carried down with the forceps, or tampon holder, to dry the surface or remove any collection of urine.

Grünfeld, on the 208th page of his work, says : $A n$ die Einführung von Instrumenten in die Harnblase unter Controle des Endoscops sowie deren Verwendung daselbst konnte aus begreiflichen Gründer nicht gedacht werden. "The introduction of instruments 
into the (male) urinary bladder, under control of the endoscope, as well as their application there, was, for apparent reasons, not to be thought of," and states further on, that his investigations have thus far been confined chiefly to the female bladder, easier of examination, but much less often the seat of disease. I have found no difficulty in introducing this instrument into the bladder of the living subject without ether, but would recommend anæsthesia for all bladder exploration. In urethral examination the local anesthetic effect of cocaine suffices.

The use of the endoscope is not by any means limited to the examination of the urethra and bladder, but may be employed with advantage in exploring numerous other cavities, such as that of the uterus, the rectum, high up, the nasal and pharyngeal cavities; and, also, sinuses and cavities following disease or injury. I see no reason why, introduced as a trocar
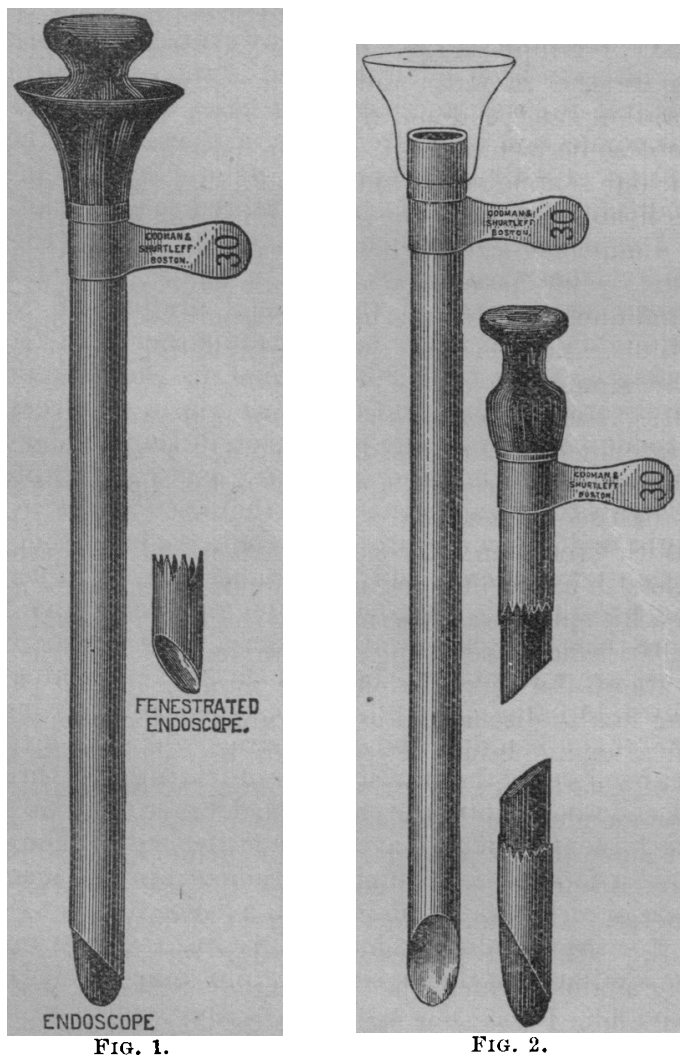

canula, or through a slight incision into the abdominal or thoracic cavities, it could not be used to advantage in the diagnosis of obscure and serious affections.

'The best light to use is reflected sunlight, and the tubes may be darkened on the inside but soon become dull enough on the inner surface to avoid trouble from light reflexes. Any topical applications made in the bladder or urethra with this instrument are much better and more scientific than those made somewhat blindly by other means.

In making the ocular end of the instrument I have preferred a simple funnel-shaped attachment, passed over the end of a tube, made like those for Professor Bigelow's evacuator. The very practical indicator being convenient for manipulation, and simple in construction.

\section{LITHOLOPAXY.}

In cousidering the changes which the above demon. strated fact suggests in litholopaxy, we have mainly to do with the process of evacuation, and here an important alteration in the construction of the evacuator is indicated. This consists in reducing the distance between the orifices of the present tube, that is the combined tube, made up of the part for insertion and the joints connected with the evacuator, from $153-4$ inches to 10 . In order to be evacuated every fragment must be lifted by the exhaust current with the column of water from the visceral orifice to the opening in the trap end of the tube, and that to materially shorten this distance much adds to the admirable working of Professor Bigelow's instrument, is readily understood.

Another, and what seems to me valuable, modification in the evacuating tubes is to have them made $s 0$ as to be introduced with a staff and have left when this is withdrawn a tube with an orifice representing more than its full calibre and corresponding with it in direction (Fig. 2), so that the fragments, instead of entering the tube at an angle, are drawn directly into its orifice by the exhaust current. The obliquity of the opening is such that the bladder is held away by the extremity of the tube and is only drawn in when the latter is so placed that the orifice lies close to the wall and in a parallel plane, and under these conditions the bladder will be drawn into the orifice of any tube. A most valuable adjunct to the evacuator, however, and one which readily prevents aspiration of the bladder wall, or "fish bite," under ordinary circumstances, is Professor Bigelow's supply-pipe attachment, by means of which the volume of water in the bladder during operation may be quickly regulated to such a nicety that the tension of the bladder wall may be always kept where aspiration is practically out of the question.

In order to shorten the tube to a length of ten inches from the visceral orifice to the end of the trap, it is necessary to omit the first joint, which, with my tube, is not needed. When the guide is withdrawn, the outer end of the tube should be elevated so as to be as much above the bladder level as possible, and the thumb placed over the orifice until the bulb is attached. In withdrawing the tube it is unnecessary to detach it from the evacuator. A little manual dexterity is thus, in part. substituted for a joint which, although it gives a finish and neatness to the apparatus and operation, is not necessary, and increases the distance which a fragment must travel in order to be caught safely within the bulb. 'The accompanying drawings illustrate the tubes as described. 'The evacuating tube is readily converted into an endoscope by attaching the ocular piece. This and the staff are made of hard rubber and the instrument is thus very light. It would seem, perhaps, that the edges of the orifice are sharp enough to cut somewhat during manipulation, but such is not the case. The canal of these tubes being perfectly straight any impacted fragment can be readily removed and the tubes can be thoroughly cleansed by forcing through them a tight wad of cotton or sponge with the staff. These tubes also admit of the passage of larger fragments than the other tubes of a corresponding size. Their simple construction makes them much cheaper than Professor Bigelow's tubes. The object of these changes is naturally to increase the rapidity of evacua- 
tion, and thus add somewhat to the efficacy of the evacuator which Professor Bigelow has already made so beautiful in its working. To any one who has studied its capabilities, by evacuating coal fragments from a glass globe, for example, and seen with what certainty they, sooner or later, are captured, I am not putting too frequent stress or compliment, if either be needed, upon the Bigelow evacuator.

If it has been my good fortune to contribute somewhat to the efficiency of this instrument, I must refer the same to the opportunities which a double service, as Dr. Bigelow's House Officer gave me, to become familiar with litholopaxy.

Coinpared under like conditions the modified evacuator removes fragments four or five times as rapidly. In a protracted operation this is, of course, a great advantage. My friend, Dr. Beach, of the Massachusetts General Hospital, has kindly used these tubes in the removal of a small stone, the fragments of which weighed 14.7 grammes. The working of the instrument was most satisfactory. I have also tested them thoroughly in evacuating fragments from the bladder of a dissecting-room subject, Dr. Whitney, the curator of the Warren Anatomical Museum, having been good enough to furnish me with a calculus.

If shortening and increasing the diameter of the shaft of a lithotrite add to its efficiency in any way, it would seem that the same urethral measurement might be taken into consideration in its construction. The length of divulsors should also be diminished so that the possibility of forcing them through the urethra into the bladder wall would be eliminated. Six inches is, I believe, sufficient length for any divulsor, and such a one is now being constructed.

\section{CATHETERIZATION.}

While an evacuating tube or an endoscope should be as short as possible, a catheter may be of any convenient length, and just what this is has probably been determined by making the instruments sufficiently long to give a good chance for manipulation, and leave length enough beyond the part grasped by the hand for introduction into the bladder. 'The standard length of catheters has thus been determined, and it is interesting to notice that nearly all urethral and bladder instruments, such as sounds, evacuating tubes and divulsors correspond in length to the ordinary metallic catheter. When, however, a catheter or tube is to be employed for washing out the vesical cavity, it should be as short, and of as large calibre, as possible, so as to best admit of the free passage of fluids and thick mucus, or other matter. In the introduction of urethral instruments it is perhaps well to remember that any elastic tube as it becomes attenuated diminishes the calibre of its canal, while on the other hand, an approximation of its walls in the longitudinal direction increases the same.

- Sir Andrew Clark has resigned from the staff of the London Hospital, where his service as physician had extended over a long period of years.

- A statue in memory of "Sister Dora" was recently dedicated in Walsall, England, the cost having been defrayed by Miss Lonsdale out of the profits which she had received from her biography of her deceased friend.

\section{A CASE OF SUPRA-PUBIC LITHOTOMY.'}

\author{
Visiting Surgeon, Boston City Hospital.
}

'The so-called modified high operation for the removal of stone from the bladder is still sub judice, and every case reported will assist in determining its proper place in practical surgery.

'There can be no doubt of the advantage of the suprapubic operation as improved by Professor Petersen in some cases, as with large stones, especially when they are hard, in the very fat where it is difficult to reach the bladder through the perineum and those complicated with disease of the kidneys, or enlargment of the prostate, and where from paralysis or anchylosis of the lower extremities it is difficult to place the patient in the lithotomy position. The present question is not to determine its application to such exceptional cases, but to find out how far the operation should succeed perineal lithotomy and litholapaxy. I suppose the advantage of the high operation are the rapidity and readiness with which the operation can be done, freedom from the danger of troublesome hæmorrhage and no possible risk to the vesicular seminales or their duct. In the following case litholapaxy was out of the question by reason of the diminished size of the urethra, while perineal lithotomy, would have been nigh impossible, owing to the partial anchylosis of the lower extremities, leaving the high operation the only means of ridding the patient of his stone.

M. C., about forty-two years of age, an ex-soldier of intemperate and dissolute habits in the past, an opium-eater at present, and thoroughly broken-down, was first seen June, 1886.

With exception of repeated attacks of gonorrhœa his health had been good until about three years ago, when his spine was fractured in the lower dorsal and lumbar regions, resulting in paraplegia. He was an inmate of the City Hospital for months at that time, being finally discharged as incurable. For about one year after his injury he emptied his bladder by the use of a catheter; the urine becoming ammonical, was recommended to have his bladder washed out, and ever since the greater part of his urine has dribbled away, although he still continues the use of a silver catheter. Of late, he has had great difficulty in passing the catheter; as he expressed it "there is something against which the instrument strikes," and to relieve him I was sent for. His condition was one of extreme filth, contents of bladder and bowels besmeared his perincum, inside of thighs and genitals: his wife having died of phthisis, none but young children had been left to attend to his wants, which accounted for the deplorable condition he presented.

There were two fistulous openings in the urethra, no doubt due to violent use of the catheter; one was in the penile portion and a second at the junction of the scrotum and perineum, through which the urine constantly ran; the perineum appeared fuller than normal. The urethra after division of meatus showed the presence of a stricture in the membranous portion permitting the passage of a No. 10 English catheter: a small size sound was introduced with difficulty into the bladder but could be only partially rotated owing to the constricted and thickened bladder. A large stone (possibly more than one) was detected, and 1 Read before the Boston Society of Medical Observation, Oct. 4 1886.

The Boston Medical and Surgical Journal as published by 